\title{
Application of polyunsaturated fatty acids in internal medicine: beyond the established cardiovascular effects
}

\author{
Arrigo F.G. Cicero, Alessandra Reggi, Angelo Parini, Claudio Borghi
}

Medical and Surgical Sciences Department, University of Bologna, Italy

Submitted: 24 September 2011

Accepted: 21 November 2011

Arch Med Sci 2012; 8, 5: 784-793

DOI: $10.5114 /$ aoms.2012.31613

Copyright ( 2012 Termedia \& Banach

\begin{abstract}
n-3 Polyunsaturated fatty acids (PUFAs) are organic acids, essential for mammals, whose deficiency is associated with different diseases. The American Heart Association recommends that all adults increase food-derived n-3 PUFA intake and also suggests that patients with documented coronary heart disease consume approximately $1 \mathrm{~g}$ of eicosapentaenoic acid and docosahexaenoic acid per day. However, recent evidence broadens their potential application to many other health disorders directly or indirectly associated with cardiovascular disease risk such as rheumatological diseases, mood depression, chronic kidney disease, chronic inflammatory lung diseases and others. These effects seem to be largely dependent on the dosages employed and on the characteristics of the selected patients. The cardiometabolic effects of PUFAs have been largely reviewed elsewhere, so the aim of our review is to point out the potential usefulness of such drugs with pleiotropic effects in the management of the actual typical aging patient, with co-morbidities and multidrug therapies.
\end{abstract}

Key words: polyunsaturated fatty acids, docosahexaenoic acid, eicosapentaenoic acid, internal medicine.

\section{Introduction}

Polyunsaturated fatty acids (PUFAs), organic acids that naturally contain more than one double bond in the aliphatic chain, are named according to the number $(>1)$, position, and configuration of such double bonds, which also largely determine their physical and biological properties. Polyunsaturated fatty acids are essential for mammals, which lack the enzyme to insert the double bond in the $n-6$ or n-3 position, and their deficiency is associated with various diseases [1]. While n-6 PUFAs are relatively abundant in a regular diet and there is no substantial evidence of their therapeutic potential when supplemented in the diet [2], n-3 PUFA supplementation is being studied as a potential treatment or preventive agent for numerous diseases (Table I). On the basis of currently available evidence, the American Heart Association ( $\mathrm{AHA}$ ) has recommended that all adults eat fish (particularly fatty fish) at least twice a week, as well as vegetables containing plant-derived $n-3$ fatty acids. The AHA also suggests that patients with documented coronary heart disease consume approximately $1 \mathrm{~g}$ of eicosapentaenoic acid (EPA) and docosahexaenoic acid (DHA) (combined) per day, from oily fish or fish-oil capsules (after consultation with a physician). The AHA recommendations also state that EPA/DHA supplements may be useful in patients with severe hypertriglyceridemia

\author{
Corresponding author: \\ Arrigo F.G. Cicero MD, PhD \\ Medical and Surgical \\ Sciences Department \\ Via Albertoni 15 \\ 40137 Bologna, Italy \\ Phone: 00393498558017 \\ Fax: 0039051390646 \\ E-mail: arrigo.cicero@unibo.it
}


(> $500 \mathrm{mg}$ of triglycerides per deciliter [5.6 mmol/l]), for whom effective doses are higher: $2 \mathrm{~g}$ to $4 \mathrm{~g}$ of EPA/DHA per day to lower triglyceride levels by $20-40 \%$ [3].

The cardiometabolic effects of PUFAs have been largely reviewed elsewhere [4], so the aim of our narrative review is to point out the potential usefulness of such drugs with pleiotropic effects in the management of the typical internal medicine patient, with polypathology and multidrug therapies. The literature search was based on PubMed references and cross-matched citations, giving a preference for data from recent randomized clinical trials and meta-analyses.

\section{Prevention of arrhythmias}

Arrhythmias are one of the leading causes of mortality after myocardial infarction. The antiarrhythmic effect of n-3 PUFAs after a myocardial infarction has been clearly demonstrated by some large trials such as the Diet and Reinfarction Trial $(n=2.033$, relative risk of total mortality $=29 \%)$ [5] and by The Gruppo Italiano per lo Studio della Sopravvivenza nell'Infarto Miocardico (GISSI)-Prevenzione Trial ( $n=11324$, RR of total mortality = $20 \%$, RR of sudden death $=49 \%$ [ [6]. Similar results have also been found in the large and more recent GISSI Heart Failure study, but mainly in patients with heart failure of ischemic origin [7].

Such results have not been confirmed by the large Alpha Omega trial carried out with lower dosage of EPA/DHA, in older patients who had a myocardial infarction a mean of 4 years before the beginning of the treatment [8]. This may suggest that the PUFA preventive activity against arrhythmias has a dosage threshold, is stronger when the treatment begins just after the event, and is probably more effective in younger patients. However, the outcome of the EPA-DHA supplementation in this study is difficult to interpret because the supplementation dose was small and its effects might have been obscured by the larger amount of ALA administered in half the groups in the comparison. In this instance, the factorial design of the study was inappropriate for the two nonindependent study drugs tested. Furthermore, the study was underpowered to detect differences between each of the four study groups.

Studies in patients surviving malignant ventricular arrhythmias of different etiologies treated with an implantable cardioverter-defibrillator (ICD) have given conflicting results, even if suggesting a trend toward a protective effect [9]. However, it seems

Table I. Examples of diseases for which clinical evidence supports the use of n-3 PUFAs as possible therapeutic agents or is inconclusive

\begin{tabular}{|c|c|c|}
\hline Variable & Clinical evidence & Inconclusive evidence \\
\hline Cardiovascular diseases & $\begin{array}{l}\text { - Post-infarct sudden death } \\
\text { - Heart failure } \\
\text { - Hypertension } \\
\text { - Endothelial dysfunction/atherosclerosis } \\
\text { - Prothrombotic syndromes }\end{array}$ & $\begin{array}{l}\text { - Arrhythmias (dose-threshold) } \\
\text { - Atrial fibrillation }\end{array}$ \\
\hline Metabolic disorders & $\begin{array}{l}\text { - Primary and secondary hypertriglyceridemias } \\
\text { - Small dense LDL level }\end{array}$ & $\begin{array}{l}\text { - Diabetes } \\
\text { - LDL level } \\
\text { - LDL oxidation }\end{array}$ \\
\hline Chronic renal diseases & $\begin{array}{l}\text { - IgA nephropathy } \\
\text { - Diabetic renal disease }\end{array}$ & $\begin{array}{l}\text { - Autosomal dominant } \\
\text { polycystic kidney disease }\end{array}$ \\
\hline Neurological diseases & $\begin{array}{l}\text { - Multiple sclerosis } \\
\text { - Some epilepsies } \\
\text { - Stroke }\end{array}$ & $\begin{array}{l}\text { - Cognitive decline } \\
\text { - Alzheimer disease } \\
\text { - Refractory epilepsy }\end{array}$ \\
\hline Psychiatric diseases & $\begin{array}{l}\text { - Depression } \\
\text { - Psychoses }\end{array}$ & \\
\hline $\begin{array}{l}\text { Rheumatological and other } \\
\text { immunological diseases }\end{array}$ & $\begin{array}{l}\text { - Osteoporosis } \\
\text { - Rheumatoid arthritis } \\
\text { - Systemic lupus erythematosus } \\
\text { - Psoriasis } \\
\text { - Atopic eczema } \\
\text { - Inflammatory bowel diseases }\end{array}$ & - Crohn's disease \\
\hline Respiratory diseases & $\begin{array}{l}\text { - Adult asthma } \\
\text { - Cystic fibrosis }\end{array}$ & - Pediatric asthma \\
\hline Eye diseases & $\begin{array}{l}\text { - Macular degeneration } \\
\text { - Dry eye }\end{array}$ & \\
\hline Others & & - La Peyronie's disease \\
\hline
\end{tabular}


that n-3 PUFAs are not effective in reducing atrial fibrillation recidivism after direct current electrical cardioversion [10].

\section{Effects on chronic heart failure}

Chronic heart failure is a highly prevalent disease in internal medicine departments. It has been supposed that n-3 PUFAs could have some protective effect against heart failure because of the effects on prevention of arrhythmias and the above listed metabolic and vascular effects. This observation has been confirmed in different trials. Supplementation with $2 \mathrm{~g}$ /day $\mathrm{n}-3$ PUFAs has been associated with significant reduction of the serum $\mathrm{N}$-terminal pro-brain natriuretic peptide level, a wellknown markers of heart failure [11]. In a recent small but well-designed double-blind randomized clinical trial carried out on severe heart failure patients, it was observed that left ventricular ejection fraction increased with n-3 PUFA treatment in a dose-dependent manner in 3 months, with the best results obtained with dosage of $4 \mathrm{~g} /$ day [12]. However, in a subgroup analysis of the GISSI$\mathrm{HF}$ trial it was observed that left ventricular ejection fraction increased with just $1 \mathrm{~g} /$ day n-3 PUFA by $8.1 \%$ at 1 year, $11.1 \%$ at 2 years, and $11.5 \%$ at 3 years vs. $6.3 \%$ at 1 year, $8.2 \%$ at 2 years, and $9.9 \%$ at 3 years in the placebo group ( $p=0.0050)$ [13].

Therefore, some lines of evidence suggest that n-3 PUFAs could have a direct protective effect on the myocardium [14]. For instance, a recent randomized clinical trial carried out on patients affected by non-ischemic dilated cardiomyopathy with minimal symptoms demonstrated that 12 months of supplementation with $2 \mathrm{~g} /$ day of $\mathrm{n}-3$ PUFAs was associated with a significant improvement of left ventricular ejection fraction, peak $\mathrm{VO}_{2}$, exercise duration, mean New York Heart Association functional class, and hospitalization rates for heart failure [15].

\section{Modulation of blood pressure levels}

Systemic hypertension is a pandemic major independent cardiovascular risk factor, and the reduction by just a few $\mathrm{mm} \mathrm{Hg}$ of systolic or diastolic blood pressure is associated with a significant reduction in the risk of developing a coronary or cerebrovascular disease [16]. Numerous randomized clinical trials have clearly demonstrated that n-3 PUFAs have an improving effect on endothelial function, especially in subjects at high risk of cardiovascular disease [17]. The antihypertensive effect of $n-3$ PUFAs has also been observed in patients at known increased cardiovascular risk such as those affected by chronic renal failure [18]. A meta-analysis of 36 randomized trials found a mean reduction in systolic blood pressure (SBP) of $2.1 \mathrm{~mm} \mathrm{Hg}$ and in diastolic blood pressure (DBP) of $1.6 \mathrm{~mm} \mathrm{Hg}$ [19], significantly inferior to that reported in some single trials [20]. The main reason for this low observed effect is that the meta-analysis included trials where low-dose or unpurified formulations were used, and where blood pressure reduction was not a main outcome of the study [21].

\section{Effects on secondary dyslipidemias}

It is well known that n-3 PUFAs have a dosedependent lowering effect on serum triglycerides [22], whose role as cardiovascular disease risk factors has been recently reconsidered [23]. Other metabolic effects of $n-3$ PUFAs on lipid profile, related to serum triglycerides reduction, are a small increase of serum high-density lipoprotein ( $\mathrm{HDL}$ ) cholesterol, a significant reduction of post-prandial lipemia and a significant increase in the volume of atherogenic small, dense low-density lipoproteins (LDLs) [24]. Hypertriglyceridemia, low HDL-C, and small, dense LDL are the atherogenic lipid triad, characterizing the lipid pattern of metabolic syndrome, diabetic dyslipidemia and familial combined hyperlipidemia, all conditions associated with a very high cardiovascular disease risk [25]. However, n-3 PUFAs have no quantitative effect on the circulating LDL [26]. Because of their virtual lack of pharmacological interaction and high safety profile, they could have a specific application in the management of hypertriglyceridemia and related dyslipidemias secondary to pharmacological treatments or diseases associated with an adverse metabolic profile. A short list of these conditions is listed below. The use of n-3 PUFAs as therapeutic agents for hypertriglyceridemia in the context of global cardiovascular disease management has recently been evaluated as cost-effective [27].

Non-alcoholic steatohepatitis (NASH) is a highly prevalent metabolic disorder, characterized by fat infiltration of the liver cells, associated with an increase of cardiovascular disease risk and diabetes, and for which no specific care is currently available [28]. n-3 PUFA seems to efficiently improve the metabolic pattern and to reduce the liver fat content of NASH patients, both in adults [29] and in children [30].

Polycystic ovary syndrome (PCOS) is characterized by relative hyperandrogenism and by an adverse metabolic profile, simulating a metabolic syndrome, usually with hypertriglyceridemia, overweight and impaired fasting glucose. Supplementation with n-3 PUFAs improves the lipid pattern and androgenic profile in PCOS patients [31].

Chronic kidney disease (CKD) is also a very frequent condition in internal medicine practice. It is associated with premature cardiovascular disease and markedly disturbed lipid metabolism manifesting as elevated triglyceride concentrations, 
reduced HDL cholesterol concentrations and a preponderance of small, dense LDL particles [32]. Beyond their known effects on dyslipidemias, $\mathrm{n}-3$ PUFAs could reduce the oxidative stress biomarkers of CKD patients [33]. Moreover, some trials show that $n-3$ PUFAs delay the rate of loss of renal function in patients with IgA nephropathy [34], but also of diabetic nephropathy [35]. In particular, in IgA nephropathy, n-3 PUFAs potentiate the antiproteinuric effect of angiotensin receptor blockers [36]. Additionally, studies of omega-3 supplementation in dialysis patients describe salutary effects on triglyceride levels and dialysis access patency [37]. These effects are also probably dose-related.

Some drugs such as second generation antipsychotics [38] and highly active antiretroviral therapy (HAART) [39] are associated with an adverse lipid profile and overall with a phenotypic pattern leading to an increased cardiovascular disease risk. Moreover, they often have a high risk of pharmacological interaction with lipid-lowering drugs. In these patients, n-3 PUFAs could contribute to better control of the lipid profile and to a useful antiinflammatory reaction [40].

In antipsychotic treated patients n-3 PUFAs have the potential to improve the lipid pattern and the drug-related arrhythmia risk [41], but also to reduce some psychosis related symptoms [42]. The n-3 PUFA supplementation in HIV patients treated with HAART is associated with a significant improvement in dyslipidemia and biomarkers of systemic inflammation level, without significant change in renal and liver enzymes [43].

The main limitation of the above listed effects is the lack of large clinical trials demonstrating the effect of n-3 PUFAs on the long-term cardiovascular prognosis of these patients.

\section{Neuroprotective action of $n-3$ polyunsaturated fatty acids}

n-3 PUFA intake is associated with reduced risk of age-related cognitive decline [44]. n-3 PUFAs are highly concentrated in the mammalian central nervous system and enhance synaptic activities in neuronal cells. They attenuate brain necrosis after hypoxic ischemic injury, principally by modulating membrane biophysical properties and maintaining integrity in functions between presynaptic and postsynaptic areas, resulting in better stabilization of intracellular ion balance in hypoxic-ischemic insult. Additionally, they alleviate brain apoptosis, by inducing antiapoptotic activities such as decreasing responses to reactive oxygen species, upregulating antiapoptotic protein expression, downregulating apoptotic protein expression, and maintaining mitochondrial integrity and function [45]. Clinical evidence shows that $n-3$ PUFAs could prevent stroke recidivisms [46], and inhibit symptomatic cerebral vasospasm and cerebral infarction after subarachnoid hemorrhage [47].

Beyond some preliminary evidence of efficacy [48], more recent trials carried out with DHA alone in Alzheimer disease patients did not show any delaying action of $n-3$ PUFAs against cognitive decline [49]. This observation could be influenced by the patient selection, the use of DHA alone, the timing of intervention and/or by the relatively short observation period. However, a lack of effect of n-3 PUFAs on cognitive decline has also been observed in the Alpha Omega Trial [50], where underdosed EPA and DHA were used, as well. Even if n-3 PUFA supplementation is associated with a significant reduction in brain atrophy in Huntington disease patients, particularly in the caudate and thalamus [51], they seem not to be effective in improving their cognitive function [52]. So, current available clinical evidence does not support the use of $n-3$ PUFA to slow cognitive decline in patients with neurodegenerative disorders, despite some positive data in subjects with mild cognitive disorders due to different causes [53].

\section{Antithrombotic effects}

Aspirin resistance is associated with unfavorable prognosis, including a higher incidence of myocardial infarction, stroke, and cardiovascular death among stable cardiovascular patients, a higher incidence of re-occlusion after peripheral angioplasty, and myonecrosis following elective percutaneous coronary interventions (PCI) [54]. The antithrombotic effect of n-3 PUFAs is still under evaluation, but it also seems to be dose-related [55]. In particular, n-3 PUFAs decrease thrombin formation and oxidative stress and favorably alter fibrin clot properties, at least in stable coronary artery disease patients undergoing percutaneous coronary intervention [56]. Always in percutaneous coronary revascularization patients, $n-3$ PUFAs added to the combination of aspirin and clopidogrel significantly potentiates the platelet response to clopidogrel [57]. Moreover, adding n-3 PUFAs to low-dose aspirin reduces aspirin resistance similarly to increase of aspirin dose [58]; this could have some positive effects in terms of gastrointestinal tolerability of aspirin, beyond all the other known n-3 PUFA actions. $n-3$ PUFAs could also exert some favorable effect in patients affected by prothrombotic conditions such as sickle cell disease [59].

\section{n-3 Polyunsaturated fatty acids in rheumatological diseases and osteoporosis}

Rheumatological and, more generally, inflammatory conditions are associated with an increased risk of cardiovascular disease, related to arrhythmias [60], metabolic factors [61], or systemic inflam- 
mation [62]. n-3 PUFAs decrease the production of inflammatory eicosanoids, cytokines, and reactive oxygen species and the expression of adhesion molecules; they act both directly (e.g., by replacing arachidonic acid as an eicosanoid substrate and inhibiting arachidonic acid metabolism) and indirectly (e.g., by altering the expression of inflammatory genes through effects on transcription factor activation), also giving rise to a family of antiinflammatory mediators, the resolvins [63]. Thus, n-3 PUFAs are potentially potent anti-inflammatory agents. Clinically their use is associated with a reduction in the need of non-steroidal anti-inflammatory drugs (NSAIDs) in patients with rheumatoid arthritis [64], with obvious consequences in terms of gastrointestinal safety. Meta-analytic data show that supplementation with n-3 PUFAs for 34 months reduces patient reported joint pain intensity (standardized mean difference [SMD]: -0.26 ; $95 \% \mathrm{Cl}:-0.49$ to $-0.03, p=0.03)$, minutes of morning stiffness (SMD: $-0.43 ; 95 \% \mathrm{Cl}:-0.72$ to -0.15 , $p=0.003)$, number of painful and/or tender joints (SMD: $-0.29 ; 95 \% \mathrm{Cl}:-0.48$ to $-0.10, p=0.003$ ), and NSAID consumption (SMD: $-0.40 ; 95 \% \mathrm{Cl}:-0.72$ to $-0.08, p=0.01$ ) [65]. n-3 PUFAs also have a positive impact on the metabolic pattern, the endothelial function and the disease activity in systemic lupus erythematosus patients [66]. Thus, n-3 PUFAs improve metabolic pattern and reduce systemic inflammation in rheumatological disorders. The anti-inflammatory effects are also evident in other inflammatory conditions such as chronic bowel diseases [67] and asthma [68].

Osteoporosis and cardiovascular diseases have emerging epidemiological and physiopathological links [69]. There are different mechanisms by which dietary fatty acids affect bone: effects on calcium balance, effects on osteoblastogenesis and osteoblast activity, change of membrane function, decrease in inflammatory cytokines such as interleukin-1 (IL-1), interleukin-6 (IL-6), and tumor necrosis factor $\alpha$ (TNF- $\alpha$ ), and modulation of peroxisome proliferator-activated receptor gamma (PPAR- $\gamma$ ) [70]. Emerging epidemiological evidence also supports an anti-osteoporotic effect of n-3 PUFAs [71], and preliminary data derived from small clinical trials suggest that $n-3$ PUFAs decrease bone reabsorption but do not increase new bone formation [72]. A recent randomized clinical trial showed that $n-3$ PUFA supplementation is synergistic with long-term aerobic exercise training in attenuating inflammation and augmenting bone mass density in postmenopausal osteoporosis [73].

\section{Depression}

Depression is also a widely prevalent (and often undetected) condition in internal medicine patients [74]. Depression is an independent risk factor for coronary heart disease and for its recidivism, so that recently the American Heart Association has recommended a 2-step screening method, consisting of the 2-item Patient Health Questionnaire (PHQ-2) followed by the 9-item Patient Health Questionnaire (PHQ-9), for identifying depression in cardiovascular patients [75]. A recent meta-analysis of 29 randomized clinical trials showed that the pooled standardized difference in mean outcome was 0.10 SD $(95 \% \mathrm{Cl}: 0.02,0.17)$ in those who received n-3 PUFAs compared with placebo. Greater effects of n-3 PUFAs were found in individuals with more severe depressive symptoms. In trials that enrolled individuals with a diagnosed depressive disorder, the combined mean difference was 0.41 ( $95 \% \mathrm{Cl}: 0.26,0.55)$, while in trials that enrolled individuals without a depressive diagnosis, no beneficial effects of n-3 PUFAs were found. The large heterogeneity among trials could be related to variation in patients' characteristics [76]. For instance, n-3 PUFAs exert a specific antidepressant activity in perimenopausal women, in whom they also reduce the incidence of hot flushes and reduce the triglyceride levels, which usually increase after menopause [77]. Moreover, the n-3 PUFA antidepressant effect seems also to be particularly evident in the elderly, where 2-month treatment with $2.5 \mathrm{~g} /$ day has been associated with improvement of the Geriatric Depression Scale (GDS) and of the physical and mental components of the Short-Form 36-Item Health Survey (SF-36) [78]. Similar results have been observed in Parkinson's disease, as well [79]. But the tested product could also strongly influence the observed effect: a further recent meta-analysis in fact suggests that EPA has greater n-3 PUFA antidepressant action than DHA [80].

\section{Tolerability and safety data}

Side effects such as fishy aftertaste are uncommon, and gastrointestinal complaints are infrequent at moderate intakes, and reduced when esterified n-3 PUFAs are used [81]. Some reports show that fish oil may worsen glycemic control in diabetes, but recent data indicate that this adverse effect is not common when diabetics are adequately treated [82]. However, data from the Women's Health Initiative show that PUFA intake higher than $2 \mathrm{~g} /$ day is associated with a significant increase in type 2 diabetes incidence [83]. Concerns have also been raised regarding adverse effects on LDL cholesterol plasma level and oxidative stress, but increases in LDL cholesterol are modest and studies into oxidative stress have been contradictory. Overall these effects are unlikely to be dominant given the apparent cardiac benefits of $n-3$ PUFAs [84]. Therefore, n-3 PUFAs may exert a dose-related effect on bleeding time, but an objective assess- 


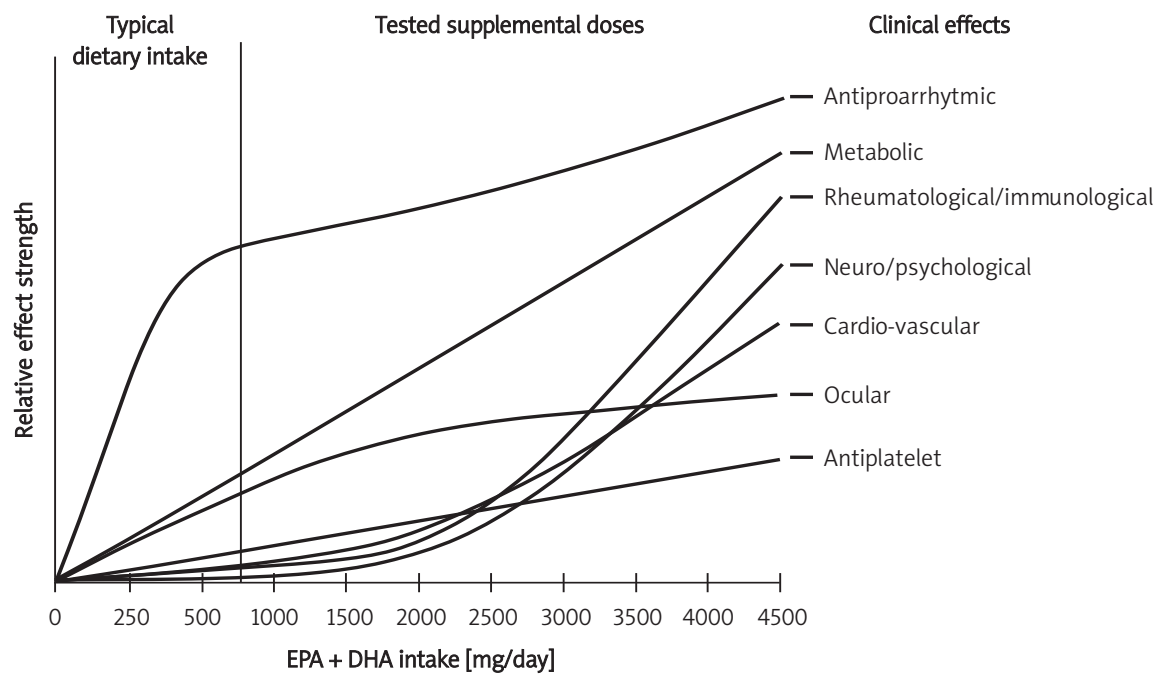

Figure 1. Dose-dependent clinical effects of polyunsaturated omega 3 fatty acids

ment of the evidence for clinically significant bleeding reveals that such concerns are unfounded [85].

More specific concerns regarding dietary fish relate to environmental contaminants, and mercury in fish may attenuate their cardioprotective effects [86]. However, a risk-benefit analysis of changes in population fish consumption concluded that reduced fish intake because of poisoning fear has a negative net public health impact [87]. Moreover, contaminants accumulate in larger, predatory fish, and consumption of a variety of fish (or of fish oil supplements) should minimize any possible adverse effects. On the other hand, consumption of equal amounts of EPA and DHA from oily fish weekly or in the form of capsules daily are nearly equally effective [88], whereas capsules are usually safer as regards possible contaminant contents, and they are not a source of other fatty acids or energy. Finally, no significant negative interaction has been observed as yet between most drugs and PUFAs [89], the only exception being a small increasing effect of anticoagulant drugs with the use of large doses [90].

\section{Discussion}

A large number of preclinical studies and some preliminary evidence suggest a therapeutic potential of n-3 PUFAs in a wide number of diseases. In some cases, the evidence quality is low and limited to single underpowered trials [91]. However, for some specific diseases, widely prevalent in internal medicine practice, and directly or indirectly related to cardiovascular disease risk, some strong evidence supports the usefulness of adequately dosed n-3 PUFAs. Beyond their known direct cardiometabolic effects, they appear to be safe and useful therapeutic tools for patients with conditions that per se could increase the cardiovascular disease risk of patients (such as CKD, NASH, depression, treatment with HAART and others) or to improve specific aspects of the conditions themselves (such as depressive traits, CKD progression, or liver fibrosis). What has to be underlined is that the greater part of the observed effect is dose-related and the PUFA amount in a standard diet or the single gram of PUFAs prescribed to post-infarction patients in order to reduce their arrhythmia risk is probably not sufficient to achieve all the PUFA relevant effects (Figure 1). Moreover, the quality of the tested products and the adequate balance between EPA and DHA is another factor strongly affecting the efficacy of this approach. However, in the cost-benefit ratio, we also have to consider that $n-3$ PUFAs could have positive effects not directly related to cardiovascular disease risk, but on very frequent conditions that can be routinely observed in internal medicine patients, such as sarcopenia [92], macular degeneration and other eye disturbances [93], psychotic disorders [94], chronic respiratory diseases [95, 96], relapsing-remitting multiple sclerosis [97], cutaneous wounds [98], and atopic eczema [99].

On the other hand, other studies do not support some indications for n-3 PUFA supplementation in specific conditions, for instance La Peyronie's disease [100], Crohn's disease [101], autosomal dominant polycystic kidney disease [102], pediatric asthma [103], and refractory epilepsy [104].

When treating patients with increased cardiovascular risk with $n-3$ PUFAs, in order to obtain the best cost-benefit ratio taking into account any comorbidities, one has to consider the adequacy of the prescribed formulation and the correct dosage employed. However, larger studies need to be carried out to determine whether n-3 PUFA sup- 
plementation could decrease the cardiovascular risk associated with all the potential clinical indications.

\section{References}

1. Das UN. Molecular basis of health and disease. SpringerVerlag, Heidelberg 2011; 101-7.

2. Simopoulos AP. The importance of the omega-6/omega3 fatty acid ratio in cardiovascular disease and other chronic diseases. Exp Biol Med 2008; 233: 674-88.

3. Kris-Etherton PM, Harris WS, Appel LJ. Omega-3 fatty acids and cardiovascular disease: new recommendations from the American Heart Association. Arterioscler Thromb Vasc Biol 2003; 23: 151-2.

4. De Caterina R. n-3 Fatty acids in cardiovascular disease. N Engl J Med 2011; 364: 2439-50.

5. Burr ML, Fehily AM, Gilbert JF, et al. Effects of changes in fat, fish, and fibre intakes on death and myocardial reinfarction: Diet and Reinfarction Trial (DART). Lancet 1989; 2: 757-61.

6. Marchioli R, Barzi F, Bomba E, et al. Early protection against sudden death by $n-3$ polyunsaturated fatty acids after myocardial infarction: time-course analysis of the results of the Gruppo Italiano per lo Studio della Sopravvivenza nell'Infarto Miocardico (GISSI)-Prevenzione. Circulation 2002; 105: 1897-903.

7. Tavazzi L, Maggioni AP, Marchioli R, et al. Effect of $n-3$ polyunsaturated fatty acids in patients with chronic heart failure (the GISSI-HF trial): a randomised, double blind, placebo-controlled trial. Lancet 2008; 372: 1223-30.

8. Kromhout D, Giltay EJ, Geleijnse JM; Alpha Omega Trial Group. n-3 Fatty acids and cardiovascular events after myocardial infarction. N Engl J Med 2010; 363: 2015-26.

9. Finzi AA, Latini R, Barlera S, et al. Effects of $n-3$ polyunsaturated fatty acids on malignant ventricular arrhythmias in patients with chronic heart failure and implantable cardioverter-defibrillators: a substudy of the Gruppo Italiano per lo Studio della Sopravvivenza nell'Insufficienza Cardiaca (GISSI-HF) trial. Am Heart J 2011; 161: 338-43.

10. Bianconi L, Calò L, Mennuni M, et al. n-3 polyunsaturated fatty acids for the prevention of arrhythmia recurrence after electrical cardioversion of chronic persistent atrial fibrillation: a randomized, double-blind, multicentre study. Europace 2011; 13: 174-81.

11. Zhao YT, Shao L, Teng LL, et al. Effects of $n-3$ polyunsaturated fatty acid therapy on plasma inflammatory markers and $\mathrm{N}$-terminal pro-brain natriuretic peptide in elderly patients with chronic heart failure. J Int Med Res 2009; 37: 1831-41.

12. Moertl D, Hammer A, Steiner S, Hutuleac R, Vonbank K, Berger R. Dose-dependent effects of omega-3-polyunsaturated fatty acids on systolic left ventricular function, endothelial function, and markers of inflammation in chronic heart failure of nonischemic origin: a double-blind, placebo-controlled, 3-arm study. Am Heart J 2011; 161: 915.e1-9.

13. Ghio S, Scelsi L, Latini R, et al.; GISSI-HF investigators. Effects of $n-3$ polyunsaturated fatty acids and of rosuvastatin on left ventricular function in chronic heart failure: a substudy of GISSI-HF trial. Eur J Heart Fail 2010; 12 1345-53.

14. Bei R, Frigiola A, Masuelli L, et al. Effects of omega-3 polyunsaturated fatty acids on cardiac myocyte protection. Front Biosci 2011; 16: 1833-43.

15. Nodari S, Triggiani M, Campia U, et al. Effects of $n-3$ polyunsaturated fatty acids on left ventricular function and functional capacity in patients with dilated cardiomyopathy. J Am Coll Cardiol 2011; 57: 870-9.

16. Sethi A, Arora RR. Ambulatory blood pressure as a predictor of cardiovascular risk. Arch Med Sci 2009; 5: 3-9.

17. Egert S, Stehle P. Impact of $\mathrm{n}-3$ fatty acids on endothelial function: results from human interventions studies. Curr Opin Clin Nutr Metab Care 2011; 14: 121-31.

18. Mori TA, Burke V, Puddey I, et al. The effects of [omega]3 fatty acids and coenzyme Q10 on blood pressure and heart rate in chronic kidney disease: a randomized controlled trial. J Hypertens 2009; 27: 1863-72.

19. Geleijnse JM, Giltay EJ, Grobbee DE, Donders AR, Kok FJ. Blood pressure response to fish oil supplementation: metaregression analysis of randomized trials. J Hypertens 2002; 20: 1493-9.

20. Cicero AF, Derosa G, Di Gregori V, Bove M, Gaddi AV, Borghi C. Omega 3 polyunsaturated fatty acids supplementation and blood pressure levels in hypertriglyceridemic patients with untreated normal-high blood pressure and with or without metabolic syndrome: a retrospective study. Clin Exp Hypertens 2010; 32: 137-44.

21. Cicero AF, Ertek S, Borghi C. Omega-3 polyunsaturated fatty acids: their potential role in blood pressure prevention and management. Curr Vasc Pharmacol 2009; 7: 330-7.

22. Skulas-Ray AC, Kris-Etherton PM, Harris WS, Vanden Heuvel JP, Wagner PR, West SG. Dose-response effects of omega-3 fatty acids on triglycerides, inflammation, and endothelial function in healthy persons with moderate hypertriglyceridemia. Am J Clin Nutr 2011; 93: 243-52.

23. Watts GF, Karpe F. Triglycerides and atherogenic dyslipidaemia: extending treatment beyond statins in the high-risk cardiovascular patient. Heart 2011; 97: 350-6.

24. Masson CJ, Mensink RP. Exchanging saturated fatty acids for $(n-6)$ polyunsaturated fatty acids in a mixed meal may decrease postprandial lipemia and markers of inflammation and endothelial activity in overweight men. J Nutr 2011; 141: 816-21.

25. Musunuru K. Atherogenic dyslipidemia: cardiovascular risk and dietary intervention. Lipids 2010; 45: 907-14.

26. Maki KC, Lawless AL, Kelley KM, et al. Effects of prescription omega-3-acid ethyl esters on fasting lipid profile in subjects with primary hypercholesterolemia. J Cardiovasc Pharmacol 2011; 57: 489-94.

27. Samuel S, Peskin B, Arondekar B, et al. Estimating health and economic benefits from using prescription omega-3 fatty acids in patients with severe hypertriglyceridemia. Am J Cardiol 2011; 108: 691-7.

28. Pascale A, Pais R, Ratziu V. An overview of nonalcoholic steatohepatitis: past, present and future directions. J Gastrointestin Liver Dis 2010; 19: 415-23.

29. Masterton GS, Plevris JN, Hayes PC. Review article: omega-3 fatty acids - a promising novel therapy for nonalcoholic fatty liver disease. Aliment Pharmacol Ther 2010; 31: 679-92.

30. Nobili V, Bedogni G, Alisi A, et al. Docosahexaenoic acid supplementation decreases liver fat content in children with non-alcoholic fatty liver disease: double-blind randomised controlled clinical trial. Arch Dis Child 2011; 96: 350-3.

31. Phelan N, O'Connor A, Kyaw Tun T, et al. Hormonal and metabolic effects of polyunsaturated fatty acids in young women with polycystic ovary syndrome: results from a cross-sectional analysis and a randomized, placebo- 
controlled, crossover trial. Am J Clin Nutr 2011; 93: 652-62.

32. Lewis D, Haynes R, Landray MJ. Lipids in chronic kidney disease. J Ren Care 2010; 36: 27-33.

33. Bouzidi N, Mekki K, Boukaddoum A, Dida N, Kaddous A, Bouchenak M. Effects of omega-3 polyunsaturated fattyacid supplementation on redox status in chronic renal failure patients with dyslipidemia. J Ren Nutr 2010; 20: 321-8.

34. Uchiyama-Tanaka Y, Mori Y. Effects of eicosapentaenoic acid supplementation on immunoglobulin A nephropathy. Ther Apher Dial 2010; 14: 303-7.

35. Wong CY, Yiu KH, Li SW, et al. Fish-oil supplement has neutral effects on vascular and metabolic function but improves renal function in patients with type 2 diabetes mellitus. Diabet Med 2010; 27: 54-60.

36. Ferraro PM, Ferraccioli GF, Gambaro G, Fulignati P, Costanzi S. Combined treatment with renin-angiotensin system blockers and polyunsaturated fatty acids in proteinuric IgA nephropathy: a randomized controlled trial. Nephrol Dial Transplant 2009; 24: 156-60.

37. Friedman AN. Omega-3 fatty acid supplementation in advanced kidney disease. Semin Dial 2010; 23: 396-400.

38. Correll CU, Kane JM, Manu P. Obesity and coronary risk in patients treated with second-generation antipsychotics. Eur Arch Psychiatry Clin Neurosci 2011; 261: 417-23.

39. Tien PC, Schneider MF, Cox C, et al. HIV, HAART, and lipoprotein particle concentrations in the Women's Interagency HIV Study. AIDS 2010; 24: 2809-17.

40. Thusgaard M, Christensen JH, Mørn B, et al. Effect of fish oil ( $n-3$ polyunsaturated fatty acids) on plasma lipids, lipoproteins and inflammatory markers in HIV-infected patients treated with antiretroviral therapy: a randomized, double-blind, placebo-controlled study. Scand J Infect Dis 2009; 41: 760-6.

41. Cysneiros RM, Terra VC, Machado HR, et al. May the best friend be an enemy if not recognized early: possible role of omega-3 against cardiovascular abnormalities due to antipsychotics in the treatment of autism. Arq Neuropsiquiatr 2009; 67: 922-6.

42. Reddy R, Fleet-Michaliszyn S, Condray R, Yao JK, Keshavan MS, Reddy R. Reduction in perseverative errors with adjunctive ethyl-eicosapentaenoic acid in patients with schizophrenia: preliminary study. Prostaglandins Leukot Essent Fatty Acids 2011; 84: 79-83.

43. Manfredi R. Management of hypertriglyceridaemia caused by combination antiretroviral therapy in HIV-infected patients: role of omega-3 polyunsaturated fatty acids at different dosages, compared with fibrates. Int J STD AIDS 2010; 21: 73-4.

44. Gorby HE, Brownawell AM, Falk MC. Do specific dietary constituents and supplements affect mental energy? Review of the evidence. Nutr Rev 2010; 68: 697-718.

45. Mayurasakorn K, Williams JJ, Ten VS, Deckelbaum RJ. Docosahexaenoic acid: brain accretion and roles in neuroprotection after brain hypoxia and ischemia. Curr Opin Clin Nutr Metab Care 2011; 14: 158-67.

46. Tanaka K, Ishikawa Y, Yokoyama M, et al.; JELIS Investigators, Japan. Reduction in the recurrence of stroke by eicosapentaenoic acid for hypercholesterolemic patients: subanalysis of the JELIS trial. Stroke 2008; 39: 2052-8.

47. Yoneda H, Shirao S, Kurokawa T, Fujisawa H, Kato S, Suzuki M. Does eicosapentaenoic acid (EPA) inhibit cerebral vasospasm in patients after aneurysmal subarachnoid hemorrhage? Acta Neurol Scand 2008; 118: 54-9.
48. Terano T, Fujishiro S, Ban T, et al. Docosahexaenoic acid supplementation improves the moderately severe dementia from thrombotic cerebrovascular diseases. Lipids 1999; 34: 345-46.

49. Quinn JF, Raman R, Thomas RG, et al. Docosahexaenoic acid supplementation and cognitive decline in Alzheimer disease: a randomized trial. JAMA 2010; 304: 1903-11.

50. Geleijnse JM, Giltay EJ, Kromhout D. Effects of n-3 fatty acids on cognitive decline: a randomized, double-blind, placebo-controlled trial in stable myocardial infarction patients. Alzheimers Dement 2011 Oct 2. [Epub ahead of print].

51. Puri BK, Bydder GM, Manku MS, Clarke A, Waldman AD, Beckmann CF. Reduction in cerebral atrophy associated with ethyl-eicosapentaenoic acid treatment in patients with Huntington's disease. J Int Med Res 2008; 36: 896-905.

52. Huntington Study Group TREND-HD Investigators. Randomized controlled trial of ethyl-eicosapentaenoic acid in Huntington disease: the TREND-HD study. Arch Neurol 2008; 65: 1582-9.

53. Johnson EJ, McDonald K, Caldarella SM, Chung HY, Troen AM, Snodderly DM. Cognitive findings of an exploratory trial of docosahexaenoic acid and lutein supplementation in older women. Nutr Neurosci 2008; 11: 75-83.

54. Catakoglu AB, Aytekin S, Celebi H, et al. The influence of aspirin resistance on non-fatal coronary events following percutaneous coronary interventions. Arch Med Sci 2009; 5: 531-8.

55. Mann NJ, O'Connell SL, Baldwin KM, Singh I, Meyer BJ. Effects of seal oil and tuna-fish oil on platelet parameters and plasma lipid levels in healthy subjects. Lipids 2010; 45: 669-81.

56. Gajos G, Zalewski J, Rostoff P, Nessler J, Piwowarska W, Undas A. Reduced thrombin formation and altered fibrin clot properties induced by polyunsaturated omega- 3 fatty acids on top of dual antiplatelet therapy in patients undergoing percutaneous coronary intervention (OMEGA-PCl clot). Arterioscler Thromb Vasc Biol 2011; 31: 1696-702.

57. Gajos G, Rostoff P, Undas A, Piwowarska W. Effects of polyunsaturated omega- 3 fatty acids on responsiveness to dual antiplatelet therapy in patients undergoing percutaneous coronary intervention: the OMEGA-PCI (OMEGA-3 fatty acids after pci to modify responsiveness to dual antiplatelet therapy) study. J Am Coll Cardiol 2010; 55: 1671-8.

58. Lev EI, Solodky A, Harel N, et al. Treatment of aspirinresistant patients with omega-3 fatty acids versus aspirin dose escalation. J Am Coll Cardiol 2010; 55: 114-21.

59. Okpala I, Ibegbulam O, Duru A, et al. Pilot study of omega-3 fatty acid supplements in sickle cell disease. APMIS 2011; 119: 442-8.

60. Eisen A, Arnson Y, Dovrish Z, Hadary R, Amital H. Arrhythmias and conduction defects in rheumatological diseases: a comprehensive review. Semin Arthritis Rheum 2009; 39: 145-56.

61. Pereira RM, de Carvalho JF, Bonfá E. Metabolic syndrome in rheumatological diseases. Autoimmun Rev 2009; 8: 415-9.

62. Roifman I, Beck PL, Anderson TJ, Eisenberg MJ, Genest J. Chronic inflammatory diseases and cardiovascular risk: a systematic review. Can J Cardiol 2011; 27: 174-82.

63. Calder PC. n-3 polyunsaturated fatty acids, inflammation, and inflammatory diseases. Am J Clin Nutr 2006; 83 (6 Suppl): 1505S-19S. 
64. Galarraga B, Ho M, Youssef HM, et al. Cod liver oil (n-3 fatty acids) as an non-steroidal anti-inflammatory drug sparing agent in rheumatoid arthritis. Rheumatology 2008; 47: 665-9.

65. Goldberg RJ, Katz J. A meta-analysis of the analgesic effects of omega-3 polyunsaturated fatty acid supplementation for inflammatory joint pain. Pain 2007; 129: 210-23.

66. Wright SA, O'Prey FM, McHenry MT, et al. A randomised interventional trial of omega-3-polyunsaturated fatty acids on endothelial function and disease activity in systemic lupus erythematosus. Ann Rheum Dis 2008; 67: 841-8.

67. Triantafillidis JK, Merikas E, Georgopoulos F. Current and emerging drugs for the treatment of inflammatory bowel disease. Drug Des Devel Ther 2011; 5: 185-210.

68. Schubert R, Kitz R, Beermann C, et al. Effect of n-3 polyunsaturated fatty acids in asthma after low-dose allergen challenge. Int Arch Allergy Immunol 2009; 148: 321-9.

69. Eastell R, Newman C, Crossman DC. Cardiovascular disease and bone. Arch Biochem Biophys 2010; 503: 78-83.

70. Maggio M, Artoni A, Lauretani $F$, et al. The impact of omega-3 fatty acids on osteoporosis. Curr Pharm Des 2009; 15: 4157-64.

71. Farina EK, Kiel DP, Roubenoff R, Schaefer EJ, Cupples LA, Tucker KL. Protective effects of fish intake and interactive effects of long-chain polyunsaturated fatty acid intakes on hip bone mineral density in older adults: the Framingham Osteoporosis Study. Am J Clin Nutr 2011; 93 : 1142-51.

72. Salari Sharif $P$, Asalforoush M, Ameri F, Larijani B, Abdollahi $M$. The effect of $n-3$ fatty acids on bone biomarkers in Iranian postmenopausal osteoporotic women: a randomized clinical trial. Age 2010; 32: 179-86.

73. Tartibian B, Maleki BH, Kanaley J, Sadeghi K. Long-term aerobic exercise and omega-3 supplementation modulate osteoporosis through inflammatory mechanisms in postmenopausal women: a randomized, repeated measures study. Nutr Metab 2011; 8: 71.

74. Lépine JP, Briley M. The increasing burden of depression. Neuropsychiatr Dis Treat 2011; 7 (Suppl 1): 3-7.

75. Elderon L, Smolderen KG, Na B, Whooley MA. Accuracy and prognostic value of American Heart Associationrecommended depression screening in patients with coronary heart disease: data from the heart and soul study. Circ Cardiovasc Qual Outcomes 2011 Aug 23 [Epub ahead of print].

76. Appleton KM, Rogers PJ, Ness AR. Updated systematic review and meta-analysis of the effects of $n-3$ long-chain polyunsaturated fatty acids on depressed mood. Am J Clin Nutr 2010; 91: 757-70.

77. Freeman MP, Hibbeln JR, Silver M, et al. Omega-3 fatty acids for major depressive disorder associated with the menopausal transition: a preliminary open trial. Menopause 2011; 18: 279-84.

78. Rondanelli M, Giacosa A, Opizzi A, et al. Long chain omega 3 polyunsaturated fatty acids supplementation in the treatment of elderly depression: effects on depressive symptoms, on phospholipids fatty acids profile and on health-related quality of life. J Nutr Health Aging 2011; 15: 37-44.

79. da Silva TM, Munhoz RP, Alvarez C, et al. Depression in Parkinson's disease: a double-blind, randomized, placebocontrolled pilot study of omega-3 fatty-acid supplementation. J Affect Disord 2008; 111: 351-9.

80. Martins JG. EPA but not DHA appears to be responsible for the efficacy of omega-3 long chain polyunsaturated fatty acid supplementation in depression: evidence from a meta-analysis of randomized controlled trials. J Am Coll Nutr 2009; 28: 525-42.

81. Bays HE. Safety considerations with omega-3 fatty acid therapy. Am J Cardiol 2007; 99 (6A): 35-43.

82. Nettleton JA, Katz R. n-3 long-chain polyunsaturated fatty acids in type 2 diabetes: a review. J Am Diet Assoc 2005; 105: 428-40.

83. Djoussé L, Gaziano JM, Buring JE, Lee IM. Dietary omega3 fatty acids and fish consumption and risk of type 2 diabetes. Am J Clin Nutr 2011; 93: 143-50.

84. Hooper L, Thompson RL, Harrison RA, et al. Risks and benefits of omega 3 fats for mortality, cardiovascular disease, and cancer: systematic review. Br Med J 2006; 332: 752-60.

85. Harris WS. Expert opinion: omega-3 fatty acids and bleeding-cause for concern? Am J Cardiol 2007; 99 (6A): 44C-6C.

86. Guallar E, Sanz-Gallardo MI, van't Veer P, et al. Mercury, fish oils, and the risk of myocardial infarction. Heavy Metals and Myocardial Infarction Study Group. N Engl J Med 2002; 347: 1747-54.

87. Cohen JT, Bellinger DC, Connor WE, et al. A quantitative risk-benefit analysis of changes in population fish consumption. Am J Prev Med 2005; 29: 325-34.

88. Harris WS, Pottala JV, Sands SA, Jones PG. Comparison of the effects of fish and fish oil capsules on the n-3 fatty acid content of blood cells and plasma phospholipids. Am J Clin Nutr 2007; 86: 1621-5.

89. Di Minno MN, Tremoli E, Tufano A, Russolillo A, Lupoli R, Di Minno G. Exploring newer cardioprotective strategies: omega-3 fatty acids in perspective. Thromb Haemost 2010; 104: 664-80.

90. Harris WS. Expert opinion: omega-3 fatty acids and bleeding-cause for concern? Am J Cardiol 2007; 99 (6A): 44C-6C.

91. Calder PC, Yaqoob P. Omega-3 polyunsaturated fatty acids and human health outcomes. Biofactors 2009; 35: 266-72.

92. Smith GI, Atherton P, Reeds DN, et al. Dietary omega-3 fatty acid supplementation increases the rate of muscle protein synthesis in older adults: a randomized controlled trial. Am J Clin Nutr 2011; 93: 402-12.

93. Wojtowicz JC, Butovich I, Uchiyama E, Aronowicz J, Agee S, McCulley JP. Pilot, prospective, randomized, double-masked, placebo-controlled clinical trial of an omega-3 supplement for dry eye. Cornea 2011; 30: 308-14.

94. Amminger GP, Schäfer MR, Papageorgiou K, et al. Longchain omega-3 fatty acids for indicated prevention of psychotic disorders: a randomized, placebo-controlled trial. Arch Gen Psychiatry 2010; 67: 146-54.

95. Lindemann J, David Pampe E, Peterkin JJ, Orozco-Cronin P, Belofsky G, Stull D. Clinical study of the effects on asthmarelated QOL and asthma management of a medical food in adult asthma patients. Curr Med Res Opin 2009; 25: 2865-75.

96. Olveira G, Olveira C, Acosta E, et al. Fatty acid supplements improve respiratory, inflammatory and nutritional parameters in adults with cystic fibrosis. Arch Bronconeumol 2010; 46: 70-7.

97. Weinstock-Guttman B, Baier M, Park Y, et al. Low fat dietary intervention with omega-3 fatty acid supplementation in multiple sclerosis patients. Prostaglandins Leukot Essent Fatty Acids 2005; 73: 397-404.

98. McDaniel JC, Belury M, Ahijevych K, Blakely W. Omega-3 fatty acids effect on wound healing. Wound Repair Regen 2008; 16: 337-45. 
99. Koch C, Dölle S, Metzger M, et al. Docosahexaenoic acid (DHA) supplementation in atopic eczema: a randomized, double-blind, controlled trial. Br J Dermatol 2008; 158: 786-92.

100. Safarinejad MR. Efficacy and safety of omega-3 for treatment of early-stage Peyronie's disease: a prospective, randomized, double-blind placebo-controlled study. J Sex Med 2009; 6: 1743-54.

101. Feagan BG, Sandborn WJ, Mittmann U, et al. Omega-3 free fatty acids for the maintenance of remission in Crohn disease: the EPIC randomized controlled trials. JAMA 2008; 299: 1690-7.

102. Higashihara E, Nutahara K, Horie S, et al. The effect of eicosapentaenoic acid on renal function and volume in patients with ADPKD. Nephrol Dial Transplant 2008; 23: 2847-52.

103. Haidopoulou K, Hatzistilianou M, Petridou A, et al. Plasma fatty acids in asthmatic children of Northern Greece. Arch Med Sci 2009; 5: 51-6.

104. Bromfield E, Dworetzky B, Hurwitz S, et al. A randomized trial of polyunsaturated fatty acids for refractory epilepsy. Epilepsy Behav 2008; 12: 187-90. 